\title{
Phosphate of Aluminum as Corrosion Inhibitor for Steel in $\mathrm{H}_{3} \mathrm{PO}_{4}$
}

\author{
L. Malki Alaoui ${ }^{1}$, S. Kertit ${ }^{2}$, A. Bellaouchou ${ }^{1}$, A. Guenbour ${ }^{1}$, \\ A. Benbachir ${ }^{1}$, B. Hammouti ${ }^{3, *}$ \\ ${ }^{1}$ Laboratoire d'Electrochimie et Corrosion, Faculté de Sciences, Rabat, Morocco \\ ${ }^{2}$ Ecole Supérieure d'Optique Appliquée (ESOA), Rabat, Morocco \\ ${ }^{3}$ Laboratoire de Chimie Appliquée et Environnement, Faculté des Sciences, B.P. 717, Oujda, \\ Morocco
}

Received $28^{\text {th }}$ December 2007; accepted $1^{\text {st }}$ February 2008

\begin{abstract}
The influence of phosphate of aluminum (PA) on the corrosion inhibition of mild steel in phosphoric acid solution was studied using the weight-loss method. The electrochemical performance of the inhibitors was also investigated through potentiodynamic polarisation and EIS measurements. The inhibition efficiency of inhibitor increases with concentration to attain $84 \%$ at $10^{-2} \mathrm{M}$ of PA in $0.33 \mathrm{M} \mathrm{H}_{3} \mathrm{PO}_{4}$. Polarization studies show that PA is a mixed-type inhibitor and acts both on the cathodic and anodic reactions without changing the mechanism of the hydrogen evolution reaction. The inhibition efficiency of PA is temperature-dependent in the range $298-363 \mathrm{~K}$, the associated activation energy has been determined. PA adsorbs on the steel surface according to a Langmuir isotherm adsorption model.
\end{abstract}

Keywords: mild steel, phosphate of aluminum, phosphoric acid, corrosion.

\section{Introduction}

Acid solutions are generally used for the removal of undesirable scale and rust in several industrial processes. Near hydrochloric and sulphuric acid, phosphoric acid $\left(\mathrm{H}_{3} \mathrm{PO}_{4}\right)$ is a medium-strong acid, but it still shows strong corrosiveness on ferrous alloys [1-3]. Because of its low cost and availability, mild steel is widely employed in industry. The corrosion behaviour of steel in $\mathrm{H}_{3} \mathrm{PO}_{4}$ solutions (1 to $11 \mathrm{M})$ has been investigated [4]. Inhibitors are generally used to control metal dissolution. The inhibition of corrosion in acid solutions can be secured by the addition of a variety of organic compounds and has been investigated by several

\footnotetext{
* Corresponding author. E-mail address: hammoutib@yahoo.fr
} 
workers [5-10]. Inorganic inhibitors are also used to secure metals against corrosion; we cite molybdate, vanadate, halides as well as metallic ions as $\mathrm{Zn}^{2+}$, $\mathrm{Cu}^{2+}, \mathrm{Ce}^{3+} \ldots$ [11-16]. The effect of $\mathrm{Al}^{3+}$ on the corrosion of steel in molar sulphuric acid solution containing 2-mercaptobenzimidazole has been studied by Wahdan [16]. Little work appears to have been done on the inhibition of mild steel in $\mathrm{H}_{3} \mathrm{PO}_{4}$ solution. In this work, the influence of the phosphate of aluminium $\mathrm{AlPO}_{4}(\mathrm{PA})$ on inhibition of the corrosion of steel in $0.33 \mathrm{M} \mathrm{H}_{3} \mathrm{PO}_{4}$ is evaluated at various temperatures. Study of the kinetics of the corrosion of mild steel in phosphoric acid was achieved by weight loss, potentiodynamic polarization and electrochemical impedance spectroscopy methods.

\section{Experimental}

Mild steel $(0,09 \% \mathrm{P}, 0,38 \% \mathrm{Si}, 0,01 \% \mathrm{Al}, 0,05 \% \mathrm{Mn}, 0,21 \% \mathrm{C}, 0,05 \% \mathrm{~S}$ and balance $\mathrm{Fe}$ ) was used for this investigation. Steel samples were polished with different emery papers up to 1200 grade, washed thoroughly with bi-distilled water degreased and dried with acetone. The aggressive solution $\left(0.33 \mathrm{M} \mathrm{H}_{3} \mathrm{PO}_{4}\right)$ was prepared by dilution of analytical grade $85 \% \mathrm{H}_{3} \mathrm{PO}_{4}$ with double-distilled water.

Samples were weighted before and after exposure to $0.33 \mathrm{M} \mathrm{H}_{3} \mathrm{PO}_{4}$ containing various inhibitor concentrations. The solution volume was $100 \mathrm{~cm}^{3}$. The steel specimen used has a rectangular form $(1.5 \mathrm{~cm} \times 1.5 \mathrm{~cm} \times 0.05 \mathrm{~cm})$. The immersion time is $24 \mathrm{~h}$ at $298 \mathrm{~K}$.

The polarization studies were carried out on steel disc $\left(1 \mathrm{~cm}^{2}\right)$. A saturated calomel electrode SCE and a platinum electrode are used as reference and auxiliary electrode, respectively. The current-voltage characteristics are recorded with a potentiostat/galvanostat EG\&G type Princeton Applied Research Model $263 \mathrm{~A}$. Before recording the cathodic polarization curves, the steel electrode is polarised at $-800 \mathrm{mV}$ for $10 \mathrm{~min}$. The current potential curves were recorded from $-800 \mathrm{mV}$ to anodic potentials at scan rate of $1 \mathrm{mVs}^{-1}$. The solutions are deaerated with pure nitrogen.

The electrochemical impedance spectroscopy (EIS) measurements were carried out with a Tacussel electrochemical system, which included a digital potentiostat model Voltalab PGW 100 computer at $\mathrm{E}_{\text {corr }}$ after immersion in aerated solution. After determination of steady-state current at $\mathrm{E}_{\text {corr }}$, sine wave voltages $(10 \mathrm{mV})$ peak to peak, at frequencies between $100 \mathrm{kHz}$ and $10 \mathrm{mHz}$ were superimposed on the rest potential. The impedance diagrams are given in the Nyquist representation.

\section{Results and discussion}

\section{Polarisation measurements}

The cathodic and anodic polarization curves of steel in acid solution at various concentrations of PA are shown in Fig. 1. Table 1 gives values of corrosion current $\left(\mathrm{I}_{\text {corr }}\right)$, corrosion potential $\left(\mathrm{E}_{\text {corr }}\right)$, cathodic Tafel slope $\left(\mathrm{b}_{\mathrm{c}}\right)$ for PA. For 
electrochemical measurements, the inhibition efficiency is calculated by using corrosion current density as follows:

$$
E_{i} \%=\left(1-\frac{i_{\text {corr }}}{i_{\text {corr }}^{o}}\right) \cdot 100
$$

$\mathrm{i}_{\text {corr }}$ and $\mathrm{i}_{\text {corr }}$ are the corrosion current density value with and without inhibitor, respectively, determined by extrapolation of cathodic Tafel lines to the corrosion potential.

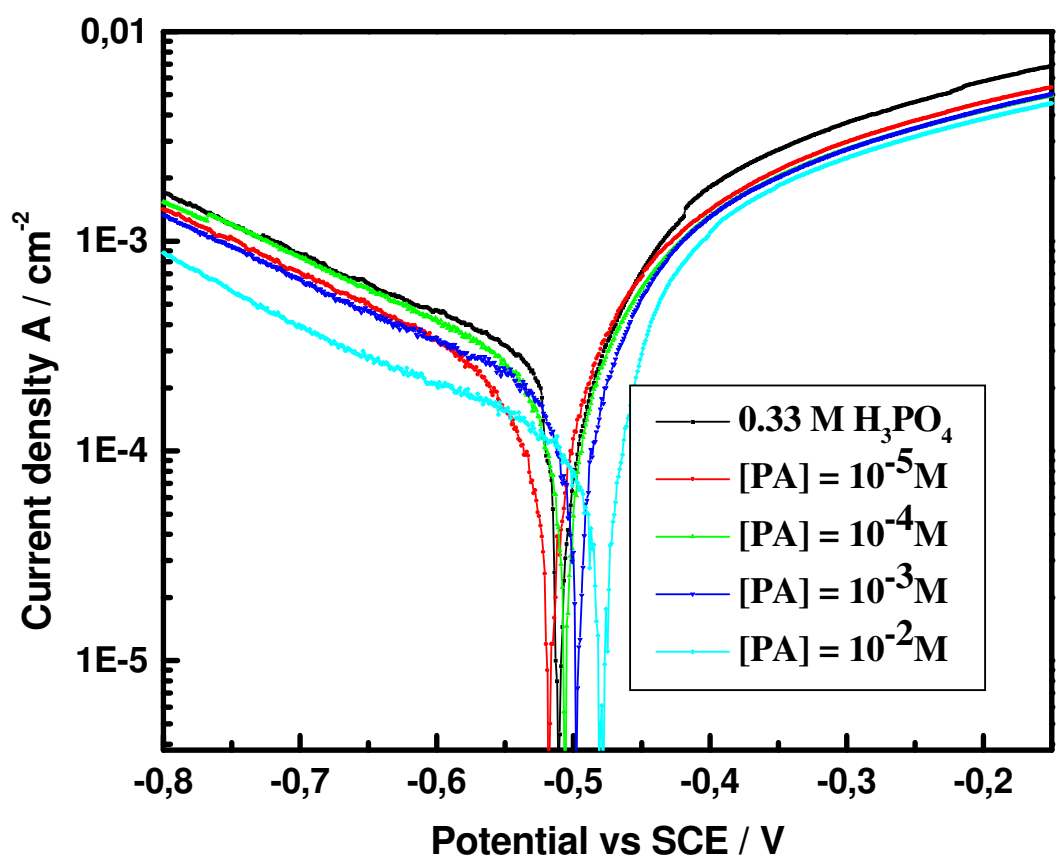

Figure 1. Polarisation curves of steel recorded in $0.33 \mathrm{M} \mathrm{H}_{3} \mathrm{PO}_{4}$ at different concentrations of PA.

The addition of PA leads to a decrease in both the cathodic and anodic current densities. This result indicates that the tested PA acts as a mixed inhibitor. The cathodic portions rise to Tafel lines indicating that the hydrogen evolution reaction is activation controlled. The addition of PA to the corrosion solution does not modify the cathodic Tafel slope $b_{c}$ and then the mechanism of the processes is not affected. The free corrosion potential determined after $30 \mathrm{~min}$ of immersion does not change in the presence of the inhibitor. These results demonstrate that the hydrogen evolution reaction is not affected in the presence of PA. E\% increases with inhibitor concentration to attain a maximum value of $85 \%$ at $10^{-2} \mathrm{M}$ of PA. PA is then a good inhibitor. 
Table 1. Electrochemical parameters of mild steel in $0.33 \mathrm{M} \mathrm{H}_{3} \mathrm{PO}_{4}$ in the presence of different concentrations of PA at $298 \mathrm{~K}$.

\begin{tabular}{|c|c|c|c|c|c|c|}
\hline Inhibitor & $\mathrm{C} / \mathrm{M}$ & $E_{\text {corr }}$ vs. SCE / mV & $i_{\text {corr }} / \mu \mathrm{A} \mathrm{cm}{ }^{-2}$ & $b_{c} / m V \operatorname{dec}^{-1}$ & $b_{a} / m V \operatorname{dec}^{-1}$ & E / \% \\
\hline $\begin{array}{c}\text { Blank } \\
\text { PA }\end{array}$ & $\begin{array}{c}- \\
10^{-5} \\
10^{-4} \\
10^{-3} \\
10^{-2}\end{array}$ & $\begin{array}{l}-511 \\
-517 \\
-505 \\
-497 \\
-480\end{array}$ & $\begin{array}{c}234 \\
126 \\
97 \\
68 \\
35\end{array}$ & $\begin{array}{l}145 \\
138 \\
149 \\
158 \\
166\end{array}$ & $\begin{array}{l}75 \\
81 \\
85 \\
79 \\
81\end{array}$ & $\begin{array}{l}- \\
46 \\
58 \\
71 \\
85\end{array}$ \\
\hline
\end{tabular}

Gravimetric measurements

The effect of addition of PA at different concentrations on the corrosion of mild steel in $0.33 \mathrm{M} \mathrm{H}_{3} \mathrm{PO}_{4}$ was studied by weight loss at $298 \mathrm{~K}$ after $24 \mathrm{~h}$ of immersion period (Table 2). The inhibition efficiency $\mathrm{E}_{\mathrm{w}} \%$ was determined by the following relation:

$$
E_{w} \%=\left(1-\frac{W_{\text {corr }}}{W_{\text {corr }}^{o}}\right) \cdot 100
$$

$\mathrm{W}_{\text {corr }}$ and $\mathrm{W}_{\text {corr }}^{\mathrm{o}}$ are the corrosion rate of steel with and without the inhibitor, respectively.

Table 2. Inhibition efficiencies for different concentrations of PA for the corrosion of mild steel in $0.33 \mathrm{M} \mathrm{H}_{3} \mathrm{PO}_{4}$ obtained from weight loss measurements.

\begin{tabular}{|c|c|c|c|}
\hline Inhibitor & Concentration / $\mathbf{~ m o l ~ L ~}$ & Corrosion rate $/ \mathbf{~ m g ~ c m}^{-\mathbf{2}} \mathbf{h}^{-\mathbf{1}}$ & $\mathbf{E}$ / \% \\
\hline \multirow{3}{*}{ Blank } & & & \\
PA & - & 11.29 & - \\
& $10^{-5}$ & 7.24 & 36 \\
& $10^{-4}$ & 5.44 & 52 \\
& $10^{-3}$ & 3.85 & 66 \\
& $10^{-2}$ & 1.82 & 84 \\
\hline
\end{tabular}

The results obtained show that the steel corrosion rate decreases with increasing inhibitor concentration. Then $\mathrm{E}(\%)$ increases with increasing inhibitor concentration. At the highest concentration of $10^{-2} \mathrm{M}, \mathrm{PA}$ has a highest inhibition efficiency of about $85 \%$. This result indicates that PA could act as good inhibitor of mild steel in phosphoric acid.

Electrochemical impedance spectroscopy

The corrosion behaviour of mild steel in acidic solution in the presence of PA was investigated by electrochemical impedance spectroscopy (EIS) at $298 \mathrm{~K}$ 
after 30 min of immersion at corrosion potential. Nyquist plots of mild steel in inhibited and uninhibited acidic solutions containing various concentrations of PA are shown in Fig. 2. The impedance parameters derived from these plots are given in Table 3 . Double layer capacitance values $\left(\mathrm{C}_{\mathrm{dl}}\right)$ and charge-transfer resistance values $\left(\mathrm{R}_{\mathrm{t}}\right)$ were obtained from impedance measurements. In the case of the electrochemical impedance spectroscopy, E (\%) is calculated by charge transfer resistance according to the relation:

$$
E_{I} \%=\left(1-\frac{R_{t}^{o}}{R_{t}}\right) .100
$$

where $\mathrm{R}_{\mathrm{t}}$ and $R_{t}^{o}$ are the charge-transfer resistance values with and without inhibitor, respectively.

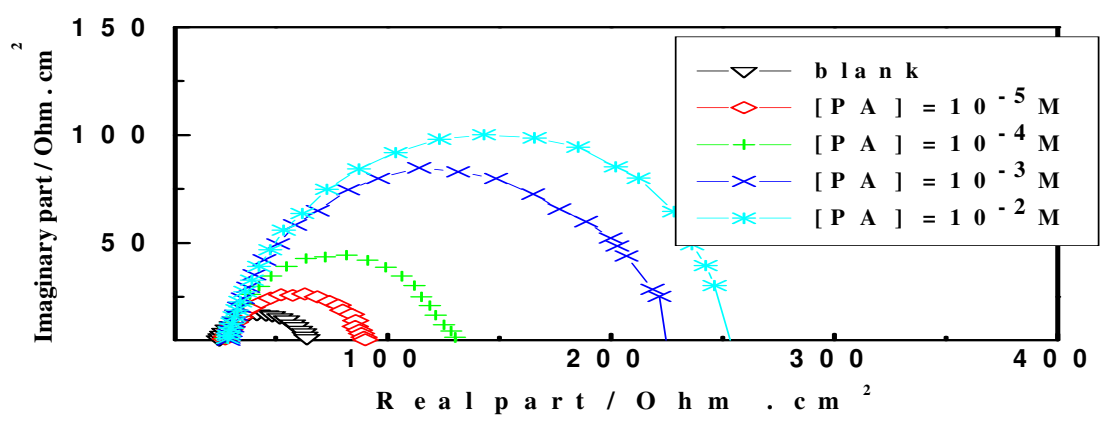

Figure 2. Nyquist diagrams for mild steel in $0.33 \mathrm{M} \mathrm{H}_{3} \mathrm{PO}_{4}$ containing different concentrations of PA.

Table 3. Impedance parameters and inhibition efficiency for the corrosion of mild steel in $0.33 \mathrm{M} \mathrm{H}_{3} \mathrm{PO}_{4}$ without and with addition of various concentrations of $\mathrm{PA}$ at $303 \mathrm{~K}$.

\begin{tabular}{|c|c|c|c|c|c|}
\hline Inhibitor & $\mathbf{C} / \mathbf{~ m o l ~ L}^{-\mathbf{1}}$ & $\mathbf{R}_{\mathbf{t}} / \mathbf{\Omega} \mathbf{c m}^{\mathbf{2}}$ & $\mathbf{f}_{\mathbf{m a x}} / \mathbf{H z}$ & $\mathbf{C}_{\mathbf{d l}} / \boldsymbol{\mu} \mathbf{F} \mathbf{~ c m}^{-\mathbf{2}}$ & $\mathbf{E} / \mathbf{\%}$ \\
\hline \multirow{3}{*}{ Blank } & & & & & \\
PA & - & 47 & 79 & 43.0 & - \\
& $10^{-5}$ & 76 & 50 & 41.9 & 43 \\
& $10^{-4}$ & 121 & 50 & 26.3 & 61 \\
& $10^{-3}$ & 214 & 43 & 17.3 & 78 \\
& $10^{-2}$ & 240 & 40 & 16.5 & 82 \\
\hline
\end{tabular}

It is found (Table 3) that, as the PA concentration increases, the $R_{t}$ values increase, but the $\mathrm{C}_{\mathrm{dl}}$ values tend to decrease. The decrease in $\mathrm{C}_{\mathrm{dl}}$ values is interpreted by the adsorption of PA on the metal surface [17]. It is apparent from Nyquist diagrams that the charge-transfer resistance value of mild steel in uninhibited $0.33 \mathrm{M} \mathrm{H}_{3} \mathrm{PO}_{4}$ solution changes significantly after the addition of the inhibitor. Electrochemical study confirms the results of the weight loss 
measurements. The PA appears to be a good inhibitor in $0.33 \mathrm{M} \mathrm{H}_{3} \mathrm{PO}_{4}$ with a maximum efficiency of $82 \%$.

\section{Effect of temperature}

The temperature can modify the interaction between the mild steel electrode and the acidic medium in the absence and the presence of the inhibitor. Polarisation curves for mild steel in $0.33 \mathrm{M} \mathrm{H}_{3} \mathrm{PO}_{4}$ without and with $\mathrm{PA}$ in the temperature range 298 - $338 \mathrm{~K}$ were recorded and the corresponding data are given in Table 4. In the studied temperature range, the corrosion current density increases with increasing temperature both in uninhibited and inhibited solutions and the inhibition efficiency of PA decreases with temperature. The corrosion current density of steel increases more rapidly with temperature in the absence of the inhibitor. These results confirm that PA acts as a good inhibitor in the range of temperature studied. The corrosion reaction can be regarded as an Arrhenius-type process, the rate being given by

$$
I_{\text {corr }}=k \quad \exp \left(\frac{E_{a}}{R T}\right)
$$

where $\mathrm{k}$ is the Arrhenius pre-exponential constant, and $\mathrm{E}_{\mathrm{a}}$ is the activation corrosion energy for the corrosion process. Fig. 3 presents the Arrhenius plots of the logarithm of the corrosion current density vs. reciprocate of temperature, for $0.33 \mathrm{M} \mathrm{H}_{3} \mathrm{PO}_{4}$, without and with addition of $\mathrm{PA}$. The $\mathrm{E}_{\mathrm{a}}$ values were determined from the slopes of these plots and are calculated to be $E_{a}=24.0$ and $41.2 \mathrm{~kJ} \mathrm{~mol}^{-1}$. The value of activation energy $\left(\mathrm{E}_{\mathrm{a}}\right)$ found is greater than that in the uninhibited solution. While the higher value of the activation energy of the process in an inhibitor's presence when compared to that in its absence is attributed to its physical adsorption, its chemisorption is pronounced in the opposite case [18]. The higher value of $\mathrm{E}_{\mathrm{a}}$ in the presence of PA compared to that in its absence and the decrease of its $\mathrm{E} \%$ with temperature increase can be interpreted as an indication of physical adsorption.

Table 4. The influence of temperature on the electrochemical parameters for mild steel electrode immersed in $0.33 \mathrm{M} \mathrm{H}_{3} \mathrm{PO}_{4}$ and in $0.33 \mathrm{M} \mathrm{H}_{3} \mathrm{PO}_{4}+10^{-2} \mathrm{M} \mathrm{PA}$.

\begin{tabular}{|c|c|c|c|c|c|}
\hline \multirow[b]{2}{*}{$\begin{array}{c}\text { Temperature } \\
\text { / K }\end{array}$} & \multicolumn{2}{|c|}{$0.33 \mathrm{M} \mathrm{H}_{3} \mathrm{PO}_{4}$} & \multicolumn{2}{|c|}{$0.33 \mathrm{M} \mathrm{H}_{3} \mathrm{PO}_{4}+10^{-2} \mathrm{MPA}$} & \multirow[b]{2}{*}{ E/ \% } \\
\hline & $\begin{array}{c}\mathbf{E}_{\text {corr }} \text { Vs. SCE } \\
/ / \mathbf{m V}\end{array}$ & $\begin{array}{c}\mathbf{i}_{\text {corr }} \\
/ \mu \mathrm{A} \mathrm{cm}^{-2}\end{array}$ & $\begin{array}{c}\mathbf{E}_{\text {corr }} \text { vs. SCE } \\
/ / \mathrm{mV}\end{array}$ & $\begin{array}{c}\mathbf{i}_{\text {corr }} \\
/ \mu \mathrm{A} \mathrm{cm}^{-2}\end{array}$ & \\
\hline 298 & -511 & 234 & -480 & 35 & 85 \\
\hline 308 & -543 & 355 & -528 & 68 & 80 \\
\hline 318 & -557 & 427 & -519 & 118 & 72 \\
\hline 328 & -527 & 565 & -517 & 194 & 66 \\
\hline 338 & -549 & 778 & -527 & 275 & 65 \\
\hline
\end{tabular}


Physical adsorption is a result of electrostatic attraction between charged metal surface and charged species in the bulk of the solution. Positively charged species can also protect the positively charged metal surface acting with a negatively charged intermediate, such as acid anions adsorbed on the metal surface $[19,20]$.

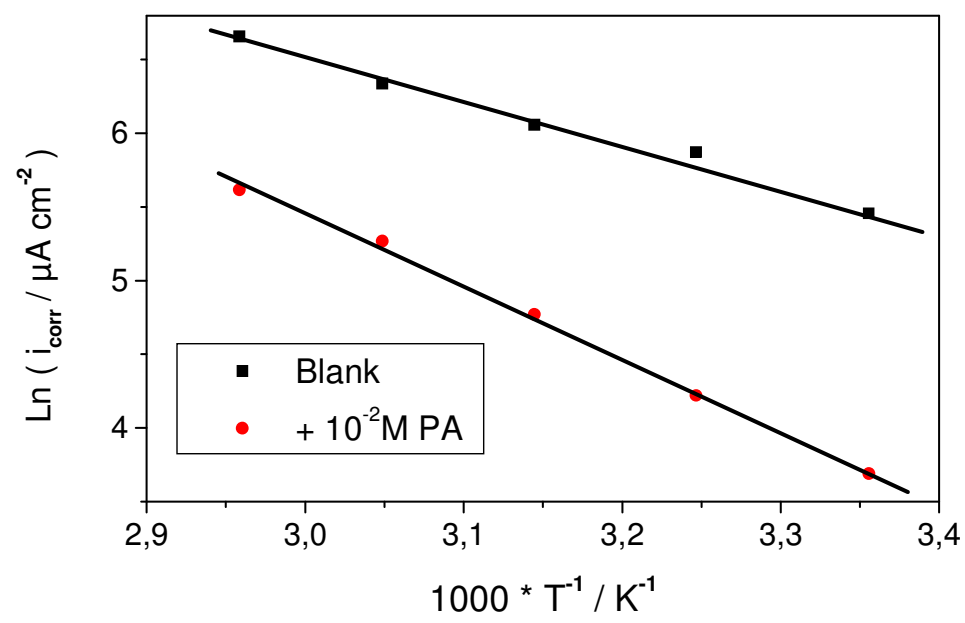

Figure 3. Arrhenius slopes calculated from corrosion current density for steel in $0.33 \mathrm{M}$ $\mathrm{H}_{3} \mathrm{PO}_{4}$ and $0.33 \mathrm{M} \mathrm{H}_{3} \mathrm{PO}_{4}+10^{-2} \mathrm{M}$ of PA.

\section{Adsorption isotherm}

The degrees of surface coverage $(\theta)$ of different concentrations of PA in $0.33 \mathrm{M}$ $\mathrm{H}_{3} \mathrm{PO}_{4}$ have been evaluated from weight loss measurements, where $\theta$ is the ratio $\mathrm{E}(\%) / 100$. The plot of $\mathrm{C} / \theta$ versus $\ln (\mathrm{C})$, (Fig. 3) shows a straight line indicating that the adsorption phenomenon of PA on the steel surface obeys to the Langmuir isotherm model

$$
\frac{C}{\theta}=\frac{1}{K}+C
$$

where $\mathrm{C}$ is the inhibitor concentration, $K$ the equilibrium constant of the adsorption process. $\Delta \mathrm{G}_{\mathrm{ads}}$, the standard free energy of adsorption, is calculated as

$$
K=\frac{1}{55.5} \exp \left(-\frac{\Delta \mathrm{G}^{\circ}}{\mathrm{RT}}\right)
$$

The linear correlation coefficient (0.9997) is close to unity and the slight deviation of the slope (1.17) from the unity is attributable to molecular interactions in the adsorbed layer which correspond to the observed physical adsorption mechanism. The obtained value of $K=7364$. The negative value of $\Delta G^{\circ}$ ads $\left(-32.0 \mathrm{~kJ} \mathrm{~mol}^{-1}\right)$ for PA suggests that the adsorption of these inhibitors onto the steel surface is a spontaneous process. Also, value of $\Delta G^{\circ}$ ads indicates 
that adsorption is due to the electrostatic interaction between charged metal surface and ionic species of inhibitor [5].

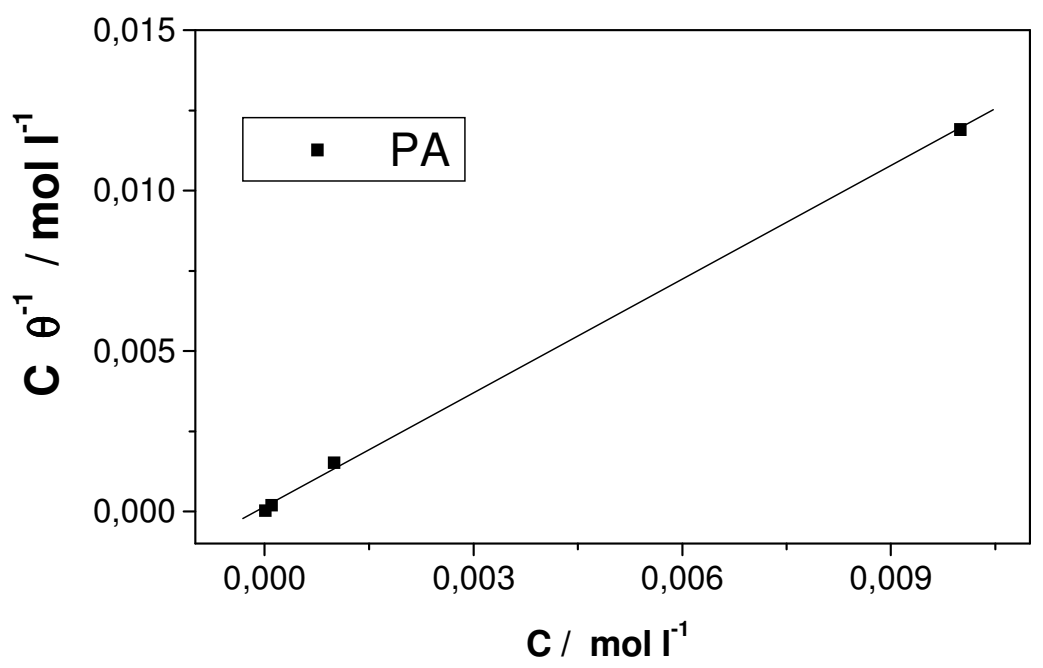

Figure 4. Langmuir isotherm adsorption model on the steel surface of PA in $0.33 \mathrm{M}$ $\mathrm{H}_{3} \mathrm{PO}_{4}$.

\section{Conclusion}

- PA inhibits the corrosion of mild steel in $0.33 \mathrm{M} \mathrm{H}_{3} \mathrm{PO}_{4}$ and acts as a mixed inhibitor in $0.33 \mathrm{M} \mathrm{H}_{3} \mathrm{PO}_{4}$ without changing the mechanism of corrosion process.

- The weight loss, electrochemical impedance spectroscopy and polarization results are in reasonably good agreement.

- The inhibition efficiency of PA decreases slightly with the temperature and the addition of PA leads to increase of corrosion activation energy.

- The adsorption of PA on the steel surface in phosphoric acid obeys the Langmuir adsorption isotherm model.

\section{Acknowledgements}

Authors are grateful to Dr. N. Alem, Department of English, University Mohammed $1^{\text {st }}$, Oujda - Morocco, for reading through this paper.

\section{References}

1. Y. Jianguo, W. Lin, V. Otieno-Alego, D.P. Schweinsberg, Corros. Sci. 37 (1995) 975.

2. M. Benabdellah, A. Aouniti, A. Dafali, B. Hammouti, M. Benkaddour, A. Yahyi, A. Ettouhami, Appl. Surf. Sci. 252 (2006) 8341.

3. G. Gunasekaran, L.R. Chauhan, Electrochim. Acta 49 (2004) 4387.

4. M. Benabdellah, B. Hammouti, Appl. Surf. Sci. 252 (2005) 1657.

5. M. Benabdellah, A. Ousslim, B. Hammouti, A. Elidrissi, A. Aouniti, A. Dafali, K. Bekkouch, M. Benkaddour, J. Appl. Electrochem. 37 (2007) 819.

6. E.E. Foad El Sherbini, Mater. Chem. Phys. 60 (1999) 286. 
7. M.A. Quraishi, D. Jamal, Corrosion 56 (2000) 156.

8. E. Otero, J.M. Bastida, Mater. Corros. 47 (1992) 133.

9. J. Uhrea, K Aramaki, J. Electrochem. Soc. 138 (1991) 3245.

10. S. Kertit, B. Hammouti, Appl. Surf. Sci. 93 (1996) 59.

11. E.H. Ait Addi, L. Bazzi, M. Elhilali, R. Salghi, B. Hammouti, M. Mihit, Appl. Surf. Sci. 253 (2006) 555.

12. G.N. Mu, X.H. Li, Q. Qu, J. Zhou, Acta Chimica Sinica 62 (2004) 2386.

13. M.A. Deyab, S.S. Abd El-Rehim, Electrochim. Acta 53 (2007) 1754.

14. M. Saremi, C. Dehghanian, M.M. Sabet, Corros. Sci. 48 (2006) 1404.

15. M.G.A. Khedr, A.M.S. Lashien, Corros. Sci. 49 (2007) 137.

16. M.H. Wahdan, Mater. Chem. Phys. 49 (1991) 135.

17. F. Bentiss, M. Lagrenee, M. Traisnel, J.C. Hornez, Corros. Sci. 41 (1999) 89.

18. A. Popova, E. Sokolova, S. Raicheva, M. Christov, Corros. Sci. 45 (2003) 33.

19. İ. Dehri, M. Özcan, Mater. Chem. Phys. 98 (2006) 316.

20. N. Hackerman, E. McCafferty, Proc. $5^{\text {th }}$ Internat. Congr. on Metallic Corrosion, Houston, TX, (1974) p 542. 